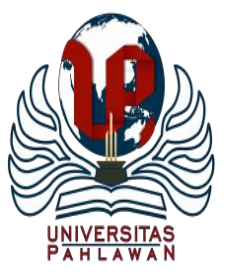

Edukatif : Jurnal Ilmu Pendidikan Volume 2 Nomor 2 Tahun 2020 Halm 144-152

EDUKATIF: JURNAL ILMU PENDIDIKAN

Research \& Learning in Education

https://edukatif.org/index.php/edukatif/index

\title{
Analisis Kebijakan Dan Pengelolaan Pendidikan Dasar Tentang Standar Kompetensi Lulusan Di Sekolah Dasar
}

\author{
Mera Putri Dewi', Sufyarma Marsidin², Ahmad Sabandi ${ }^{3}$ \\ Universitas Negeri Padang, Sumatera Barat, Indonesia ${ }^{1,2,3}$ \\ E-mail : meraputridewi14@gmail.com ${ }^{1} \underline{\text { sufyarma1954@gmail.com }}{ }^{2}$ sabandi@fip.unp.ac.id ${ }^{3}$
}

\begin{abstract}
Abstrak
Tulisan ini akan membahas mengenai analisis kebijakan dan pengelolaan pendidikan dasar tentang standar kompetensi lulusan di sekolah dasar. Standar kompetensi kelulusan digunakan untuk melihat ketercapaian hasil belajar peserta didik dalam proses pembelajaran untuk mencapai tujuan pendidikan, karena pada dasarnya pendidikan merupakan tanggung jawab negara dalam mencetak dan membentuk generasi-generasi muda yang cerdas dan berakhlak mulia. Sebagai bentuk upaya yang dilakukan negara yaitu dengan membetuk kebijakan-kebijakan dibidang pendidikan. Kebijakan ini nantinya akan dijadikan sebagai pedoman atau acuan dalam penyelenggaraan pendidikan. Dari kajian yang telah dibahas, standar kompetensi lulusan bertujuan untuk membentuk dasar pengetahuan, karakter, budi pekerti, keterampilan serta kecerdasan agar dapat mandiri dalam melanjutkan pendidikan yang lebih tinggi. Untuk itu tulisan ini sangat bermanfaat untuk guru dalam melaksanakan pembelajaran di sekolah yang harus di sesuaikan pada standar kompetensi lulusan.
\end{abstract}

Kata kunci: analisis, kebijakan, standar kompetensi lulusan, SD

\begin{abstract}
This paper will discuss policy analysis and management of basic education about the competency standards of graduates in primary schools. Graduation competency standards are used to see the achievement of student learning outcomes in the learning process to achieve educational goals, because basically education is the responsibility of the state in printing and shaping young people who are intelligent and have good character. As a form of effort carried out by the state by forming policies in the field of education. This policy will later be used as a guide or reference in the administration of education. From the studies that have been discussed, the graduate competency standard aims to form the basis of knowledge, character, character, skill and intelligence so that they can be independent in continuing higher education. For this reason, this article is very useful for teachers in implementing learning in schools that must be adjusted to the graduate competency standards.
\end{abstract}

Keywords: analysis, policies, graduates competency standards, elementary school

Copyright (c) 2020 Mera Putri Dewi, Suryarma Marsidin, Ahmad Sabandi

$\triangle$ Corresponding author :

Address : Padang, Sumbar

Email : meraputridewi14@gmail.com

ISSN 2656-8071 (Media Cetak)

Phone : 082281583206

ISSN 2656-8063 (Media Online)

DOI: $10.31004 /$ edukatif.v2i2.117

Edukatif : Jurnal Ilmu Pendidikan Vol 2 No 2 Tahun 2020 p-ISSN 2656-8063 e-ISSN 2656-8071 
145 Analisis Kebijakan Dan Pengelolaan Pendidikan Dasar Tentang Standar Kompetensi Lulusan Di Sekolah Dasar - Mera Putri Dewi, Sufyarma Marsidin, Ahmad Sabandi

DOI: 10.31004/edukatif.v2i2.117

\section{PENDAHULUAN}

Pendidikan adalah proses yang sangat berperan dalam upaya membangun bangsa ini. Pendidikan dalam hal ini merupakan tanggung jawab negara dalam mencetak dan membentuk generasi-generasi muda yang cerdas dan berakhlak mulia.

UU Sisdiknas No 20 Tahun 2003 Pasal 3 menyatakan bahwa pendidikan nasional berfungsi untuk mengembangkan keterampilan serta membentuk kepribadian bangsa yang bermartabat dalam mencerdaskan kehidupan bangsa, untuk menumbuhkembangkan potensi-potensi peserta didik untuk menjadi manusia yang bertaqwa, memiliki akhlak mulia, sehat, berilmu, kreatif, inovatif, manduri, agar menjadi warga negara yang bertanggung jawab.

Dengan adanya pendidikan diharapkan mampu merubah kepribadian bangsa ini serta agar mampu membentuk peserta didik memiliki kemampuan serta keahlian untuk menuju kehidupan yang lebih maju nantinya.

Adapun bentuk upaya yang dilakukan negara yaitu dengan membetuk kebijakankebijakan dibidang pendidikan. Kebijakan ini nantinya akan dijadikan sebagai pedoman atau acuan dalam peyelenggaraan pendidikan. Kebijakan pendidikan di Indonesia saat ini harus mengacu atau mempedomani beberapa stndar pendidikan.

Dengan adanya standar pendidikan ini nantinya akan menentukan berhasil atau tidaknya pengelolaan pendidikan baik, apakah standar pendidikan sudah diterapkan atau diimplementasi dengan baik di sekolah-sekolah atau tidak.
Pengimplementasian standar pendidikan juga akan menentukan mutu pendidikan di sekolah tersebut. Standar pendidikan di Indonesia dibentuk oleh badan standar yang merujuk pada 8 stndar pendidikan yaitu standar (kelulusan, isi, proses, pengelolaan, pendidik dan tenaga kependidikan, evaluasi, pembiayaan, sarana dan prrasarana). Semua standar tersebut diharapkan dapat dicapai oleh sekolah demi meningkatkan kualitas pendidikan yang ada di Indonesia.

\section{METODE PENELITIAN}

Penelitian ini menggunakan jenis penelitian studi kepustakaan (library research) dengan pendekatan penelitian kualitatif. Studi kepustakaan merupakan suatu studi yang digunakan untuk mengumpulkan informasi atau pengumpulan data pustaka dengan membaca dan mencatat serta mengolah bahan penelitian. Ciri-ciri dari studi kepustakaan adalah peneliti berhadapan langsung dengan teks atau naskah, data kepustakaan bersifat tetap dan siap pakai, data pustaka umumnya adalah data sekunder dalam arti peneliti mendapatan data dari tangan kedua dan bukan data orisinil dari tangan pertama di lapangan, dan kondisi data pustaka tidak dibatasi oleh ruang dan waktu (Zed, 2014).

Teknik pengumpulan data yang digunakan yaitu studi dokumentasi yaitu teknik pengumpulan data yang dilakukan dengan menganalisis isi dokumen yang berhubungan dengan masalah yang diteliti. Menurut Gunawan, analisis dilakukan dengan cara membandingkan dan memadukan dokumen-dokumen untuk membentuk suatu hasil kajian yang sistematis (Gunawan, 2013). 
Adapun analisis data yang digunakan yaitu analisis konten (content analysis). Menurut Weber menyatakan analisis konten merupakan penelitian yang memanfaatkan seperangkat prosedur untuk menarik kesimpulan yang sahih dari sebuah buku atau dokumen.

\section{HASIL DAN PEMBAHASAN PENELITIAN}

\section{Standar Kompetensi Lulusan (SKL) di SD}

Kompetensi yaitu kemampuan atau keahlian yang dipunyai oleh seseorang dalam hal bertindak, bersikap, dan berpikir yang bersifat konsistensi dan merupakan bentuk perwujudan dari sikap, pengetahuan, dan keterampilan yang dimilikinya. Demikian dengan standar kompetensi yang merupakan patokan yang harus dipenuhi dan dilaksanakan oleh siswa setelah mereka menyelesaikan kegatan belajar mengajar di satuan pendidikannya. Dalam proses belajar mengajar di satuan pendidikan harus mengacu pada SKL. SKL merupakan adalah bagian dari keseluruhan kompetensi lulusan yang sudah ditetapkan dan dilaksanakan sebagai hasil dari kegiatan belajar siswa. Dengan adanya hasil pembelajaran dari peserta didik ini, standar kompetensi lulusan dapat diukur dan dilihat agar mempermudah membuat keputusan bagi pendidik dan tenaga kependidikan dalam penentu dan pelaksana kebijakan pendidikan (Alawiyah, 2017).

SKL yang dirumuskan dalam kurikulum 2013 ditata secara berjenjang, artinya kompetensi lulusan pada jenjang pendidikan Sekolah Dasar (SD)/Madrasah
Ibtidaiyah (MI) akan dilanjutkan dan dikembangkan pada jenjang Sekolah Menengah Pertama (SMP)/Madrasah Tsanawiyah (MTs) yang selanjutnya akan dilanjutkan dan dikembangkan kembali ke jenjang Sekolah Menengah Atas (SMA)/Madrasah Aliyah (MA) (Zaini, 2015). Standar Kompetensi Lulusan merupakan muara utama pencapaian yang dituju dari semua mata pelajaran pada jenjang pendidikan tertentu (Rachmawati, 2018). Standar Kompetensi Lulusan ini dapat berguna sebagai acuan penilaian dan pemantauan dari tercapainya hasil belajar siswa dalam kegiatan pembelajaran. Dalam PP No. 19 Thn 2005 mengenai Standar Nasional Pendidikan (SNP) dijelaskan bahwa, Satndar Kompetensi Lulusan (SKL) merupakan kualifikasi kemampuan lulusan yang terdiri dari pengetahuan, sikap dan keterampilan yang dapat dijadikan sebagai acuan dalam penentuan lulus atau tidaknya peserta didik pada saat menyelesaikan kegiatan pembelajaran yang dilaksanakan tersebut (Pemerintah Republik Indonesia, 2013).

SKL (Standar kompetensi Lulusan) merupakan suatu komponen dari Standar Nasional Pendidikan. Untuk jenjang sekolah dasar (SD). Untuk kelulusan siswa ditentukan oleh ujian akhir sekolah berstandar nasional. Tujuannya yaitu untuk menilai dari pencapaian SKL secara nasional pada mata pelajaran Bahasa Indonesia, Matematika, dan Ilmu Pengetahuan Alam (IPA) dan untuk 
mengupayakan tercapainya target wajib belajar pendidikan dasar yang bermutu. Hasil dari ujian akhir nantinya digunakan sebagai salah satu bahan pertimbangan dalam pemetaan mutu satuan pendidikan dasar seleksi masuk jenjang pendidikan berikutnya, penentuan kelulusan peserta didik dari satuan pendidikan, dan dasar pembinaan dan pemberian bantuan kepada satuan pendidikan dalam upaya peningkatan mutu pendidikan (Elvina, Asrivi, Rokhman, \& Deliana, 2017).

Adapun tujuan dalam rumusan SKL yaitu sebagai pedoman dalam mengembangan dari 8 standar pendidikan yaitu standar (kelulusan, standar isi, proses, pengelolaan, pendidik dan tenaga kependidikan, evaluasi, pembiayaan, sarana dan prasarana). Standar ini merupakan akhir dari serangkaian standari dalam SNP lainnya. Standar kompetensi lulusan ini harus mengacu pada SDM yang mempedomani tujuan pendidikan yang ada di Indonesia.

Untuk dapat mengetahui ketercapaian dan kesesuaian Standar Kompetensi Lulusan (SKL) dan lulusan masing-masing satuan pendidikan serta kurikulum yang digunakan pada satuan pendidikan mestinya perlu dilakukan monitoring dan evaluasi. Untuk melakukan peninjauan (monitoring) dan evaluasi hendaknya dilakukan secara sistematis dan dilakukan secara berkala agar hasilnya menjadi input untuk menyempurnakan standar kompetensi lulusan tersebut (Rahmawati \& Anggraini, 2017).
Standar kompetensi lulusan ini telah termuat dalam Pemendikbud No. 20 Tahun 2016 mengenai Standar Kompetensi Lulusan Pendidikan Dasar dan Menegah. Permendikbud mengenai SKL ini memuat kriteria keahlian khusus atau kemampuan dari siswa agar mampu dicapai setelah siswa mengikuti proses kegiatan pembelajaran di sekolah pada tingkatan pendidikan dasar dan menengah. Untuk melihat pencapaian SKL hendaknya dilakukan peninjauan dan mengevaluasi untuk melihat ketercapaian lulusan pada tingkat satuan pendidikan apakah telah sesuai dengan standar kompetensi lulusan tersebut.

Ada tiga dimensi yang diukur pada stndar kompetensi lulusan yaitu dimensi (sikap, pengetahuan, dan keterampilan). Dimensi-dimensi tersebut saling terintegrasi menjadi satu kesatuan yang utuh dari peserta didik. Dimensi sikap pada standar kompetensi lulusan yaitu apabila peserta didik mempunyai sikap yang menunjukkan perilaku yang memiliki iman dan ketaqwaan kepada Allah SWT, memiliki karakter seperti disiplin, kejujujuran, kepedulian, tanggung jawab, dapat belajar sepanjang hayat, serta memiliki jasmani dan rohani yang sehat seperti sesuai dengan perkembangan dan pertumbuhan peserta didik lainnya alam cakupan disetiap tingkat, diawali dari lingkungan keluarga anak, lingkungan sekolah anak, lingkungan sekitar anak seperti masyarakat, bangsa, dan negara. 
Adapun dimensi yang kedua pada standar kompetensi lulusan yaitu dimensi pengetahuan. Dalam dimensi ini memiliki tingkat yang berbeda-beda sesuai dengan tahapan dan turunanya. Dalam dimensi pengetahuan peserta didik atau lulusan dituntut untuk menmiliki pengetahuan yang bersifat fakutal, berprosedural, konseptual, memiliki pengetahuan meta-kognitif sesuai dengan tingkatannya secara jelas, detail, spesifik dan komplek mengenai IPTEK, seni dan budaya, maupun humaniora serta dituntut untuk memiliki kemampuan dalam menyelesaikan permasalahan yang berkaitan dengan lingkungan keluarga, sekolah, msayarakat, alam sekitar, serta kawasan yang lebih luas lainnya seperti bangsa dan negara ataupun dalam kawasan regional dan internasional.

Dimensi yang terakhir dalam standar kompetensi lulusan yaitu dimensi keterampilan. Dalam dimensi ini peserta didik atau lulusan diharapkan memiliki kemampuan dan keterampilan yang mampu berpikir secara kritis, kreatif, inovatif, produktif, kolaboratif, mandiri, dan komunikatif sesuai dengan pendekatan-pendekatan ilmiah. Untuk tingkat sekolah dasar pendekatan ilmiah yang dimaskud akan harus sesuai dengan tingkat perkembangan anak yang selaras dengan kegiatan pembelajaran yang dilaksanakan. Sedangkan untuk tingkat menengah pertama pendekatan ilmiah yang dilaksanakan harus sesuai dengan apa yang dipelajarinya di sekolahnya dan dapat mencari referensi lain secara mandiri. Untuk tingkat mengenah atas pendekatan ilmiah yang dilaksanakan adalah lanjutan dari yang dipelajarinya pada satuan pendidikan dan sumber lain secara mndiri.

\section{Tujuan dan Fungsi dari Standar Kompetensi Lulusan}

SKL (standar komptennsi lulusan) memiliki fungsi yang sangat penting dalam menentukan kelulusan bagi peserta didik. Fungsinya yaitu sebagai acuan dalam penentuan apakah peserta didik dinyatakan lulus atau tidak setelah melaksanakan kegiatan pembelajaran di satuan pendidikan, sebagai rujukan dalam menyusun dan menuntukan satandar pendidikan lainnya, serta sebagai penunjuk dalam meningkatkan mutu pendidikan secara lebih sistematis dan holistik untuk satuan pendidikan tingkat dasar dan menegah, selain itu, juga merupakan petujuk dalam menilai dan menentukan apakah peserta didik telah memenuhi kompetensi-kompetensi yang telah ditetapkan meliputi kompetensi pada setiap muatan pelajaran yang mencakup dimensi sikap, pengetahuan, dan keterampilan (Suryati, Rochan, \& Nurmila, 2019).

Tujuan dari Standar Kompetensi Lulusan (SKL) yaitu sebagai berikut:

1) untuk terwujudnya standar Nasional dan Instusional dari kompetensi lulusan

2) merupakan arah dalam menentukan kriteria, pondasi dasar pengendalian dan quality assurance (jaminan mutu) dari lulusan 
3) dapat memperkokoh keprofesionalan sesuai penetapan standar kelulusan secara nasional sesuai dengan tuntutan institusioanal seperti visi dan misi dalam satuan pendidikan.

Dengan adanya (SKL) untuk jenjang SD dan Menengah dapat dijadikan sebagai petunjuk dan acuan utama dalam mengembangkan standar-standar pendidikan lain seperti standar isi, standar proses, standar penilaian, standar pendidik dan tenaga kependidikan, standar sarana-prasarana, standar pengelolaan serta standar pembiayaan.

Pada jenjang pendidikan dasar standar kompetensi lulusan bertujuan untuk membentuk dasar pengetahuan, karakter, budi pekerti, keterampilan serta kecerdasan agar dapat mandiri dalam melanjutkan pendidikan yang lebih tinggi. Pada jenjang pendidikan menengah pertama standar kompetensi lulusan bertujuan untuk meningkatkan dasar pengetahuan, karakter, budi pekerti, keterampilan serta kecerdasan untuk dapat berdiri sendiri dan melanjutkan pendidikan pada tingkatan yang lebih tinggi. Sedangkan pada tingkat pendidikan menengah atas dasar pengetahuan, karakter, budi pekerti, keterampilan serta kecerdasan dalam melanjutkan pendidikan pada tingkatan yang lebih tinggi sesuai dengan kejuruannya. SKL pada pendidikan dasar dan menengah maupun pendidikan non-formal dibentuk oleh (BSNP) serta ditetapkan oleh Permen.
Permendikbud No 20 Thn 2016 Tentang Stndar Kompetensi Lulusan Penddikan Dasar dan Menengah

Untuk mencapai tujuan dari pendidikan nasional harus memiliki profiil keahlian dan kemampuan dari lulusan yang termuat dalam SKL. Dalam ketentuan pasal 35 UU No. 20 Tahun 2003 menjelaskan bahwa SKL adalah bagian dari kualifikasi kemampuan dari lulusan yang terdiri dari dimensi sikap, dimensi pengetahuan, dan dimensi keterampilan siswa yang mesti dipenuhi dan dicapai pada satuan pendidikan baik ditingkat dasar maupun menegah (Permendikbud RI No. 20, 2016).

SKL terdiri dari kriteria kualifkasi kemampuann lulusan dari peserta didik yang mesti ditempuh dan dilaksanakan setelah peserta didik melaksanakan kegiatan pembelajaran pada satuan pendidikannya.

Ketercapaian dan kesesuaian anatara SKL dan lulusan dapat diketahui dari tingkatan jenjang pendidikan dan pada kurikulum yang ditetapkan di satuan pendidikan tersebut. oleh karena itu, hendaknya dilakukan monitoring atau peninjauan dan penilaian secara bertahap dan berkelajutan di setiap periodisasi. Dari kegiatan monitoring dan kegiatan evaluasi dapat dijadikan sebagai rujukan atau acuan dalam penyempurnaan SKL pada masa selanjutnya.

Untuk setiap lulusan dari jenjang satuan pendidikan dasar dan menengah harus memiliki beberpa kompetensi yang mesti 
dicapai dimensi yaitu sikap, dimensi pengetahuan, dan dimensi keterampilan. Lulusan jenjang pendidikan dasar yaitu sebagai berikut:

\section{Sikap}

Harus mempunyai sikap yang menunjukkan sikap:

1. Memiliki iman dan ketaqwaan kepada Tuhan

2. Memiliki karakter yang baik seperti kejujuran, kepedulian,

3. Tanggung jawab,

4. Dapat belajar sepnjang hayat, dan

5. Memiliki jasmani dan rohani yang sehat berdasarkan perkembangan anak pada lingkungan keluarga, sekolah, masyarakat

\section{Pengetahuan}

1. Harus memiliki pengetahuan yang bersifat faktual, kosepntual, prosedurral, dan pengetahuan meta-kognitif pada jenjang dasar berkenaan dengan: IPTEK, Seni, dan Budaya.

2. Dapat menyelesaikan permasalahan yang berkaitan dengan lingkungan siswa dan dapat mengaitkan pengetahuan dalam kontek keluarga, sekolah, masyarakat, bangsa dan negara.

\section{Keterampilan}

Harus memiliki kemampuan dan keterampilan dalam berpikir dan bertindak yang meliputi:

1. Inovasi

2. Kreativitas

3. Produktivitas,
4. Berpikir secara kritis,

5. Kemandirian,

6. Dapat berkolaborasi dan

7. Dapat berkomunikasi dengan menggunakan pendekatan ilmiah sesuai dengan tahap perkembangan anak usia sekolah dasar (Permendikbud RI No. 20, 2016).

Dalam istilah pengetahuan Factual, pengetahuan Conseptual, pengetahuan Prsedural, dan pengetahuan Metacognitif dapat dipaparkan sebagai berikut:

1. Faktual: yaitu pengetahuan yang mendasarnya berkaitan dengan IPTEK, seni dan budaya yang berkaitan dengan pribadi, lingkungan keluarga, lingkungan sekolah, lingkungan masyarakat dan alam sekitar, serta baangsa dan negara.

2. Konseptual: terminologi atau istilah yang dipakai, dikelompokkan, dikategorikan, prinsip, serta geeneralisasi yang berkaitan dengan pribadi, lingkungan keluarga, lingkungan sekolah, lingkungan masyarakat dan alam sekitar, serta bangsa dan negara.

3. Prosedural: yaitu pengetahuan yang meliputi bagimana melaksanakan sesuatu hal atau kegiiatan yang berkaitan deengan berkaitan dengan pribadi, lingkungan keluarga, lingkungan sekolah, lingkungan msyarakat dan alam sekitar, serta bangsa dan negara.

4. Metakognitif: yaitu pengetahuan mengenai kesadaran akan kekuatan dan kelemahan diri sendiri dan bagaimana 
151 Analisis Kebijakan Dan Pengelolaan Pendidikan Dasar Tentang Standar Kompetensi Lulusan Di Sekolah Dasar - Mera Putri Dewi, Sufyarma Marsidin, Ahmad Sabandi

menerapkan dalam mempelajari ilmu pengetahaan yang berkaitan dengan pribadi, lingkungan keluarga, lingkungan sekolah, lingkungan masyarakat dan alam sekitar, serta bangsa dan negara.

Tolak ukur dari dimensi sikap, dimensi pengetahuan, dan dimensi keterampilan pada jenjang satuan pendidikan harus mempertimbangkan:

a. konisi fsikologis dari anak;

b. ruang lingkup dan kedalaman;

c. berkesinambungan

d. tujuan dan fungsi dari satuan pendidikan, serta

e. lingkungan peserta didik

\section{KESIMPULAN}

SKL merupakan adalah bagian dari keseluruhan kompetensi lulusan yang sudah ditetapkan dan dilaksanakan sebagai hasil dari kegiatan belajar siswa. Dengan adanya hasil belajar dari peserta didik ini, standar kompetensi lulusan dapat diukur dan dilihat agar mempermudah membuat keputusan bagi pendidik dan tenaga kependidikan dalam penentu dan pelaksana kebijakan pendidikan. SKL terdiri dari dimensi sikap, pengetahuan, dan keterampilan.

Dengan adanya (SKL) untuk jenjang SD dapat dijadikan sebagai petunjuk dan acuan utama dalam mengembangkan standar-standar pendidikan lain seperti standar isi, standar proses, standar penilaian, standar pendidik dan tenaga kependidikan, standar sarana prasarana, standar pengelolaan serta standar pembiayaan.
Ketercapaian dan kesesuaian anatara SKL dan lulusan dapat diketahui dari masing-masing jenjang pendidikan dan pada kurikulum yang ditetapkan di satuan pendidikan tersebut. oleh karena itu, perlu dilakukan monitoring atau peninjauan dan penilaian secara bertahap dan berkelanjutan di setiap periodisasi. Dari kegiatan monitoring dan kegiatan evalusi dapat dijadikan sebagai rujukan atau acuan dalam penyempurnaan SKL pada masa selanjutnya.

\section{DAFTAR PUSTAKA}

Alawiyah, F. (2017). National Standards of Primary and Secondary Education. Aspirasi, $8(1), 81-92$.

Elvina, Q., Asrivi, S., Rokhman, F., \& Deliana, S. M. (2017). Penerapan Standar Kompetensi Lulusan Mata Pelajaran Bahasa Indonesia Sekolah Dasar. Journal of Primary Education, 6(3), 257-266.

Pemerintah Republik Indonesia. (2013). PERUBAHAN ATAS PERATURAN PEMERINTAH NOMOR 19 TAHUN 2005 TENTANG STANDAR NASIONAL PENDIDIKAN. In PERATURAN PEMERINTAH REPUBLIK INDONESIA NOMOR 32 TAHUN 2013.

Permendikbud RI No. 20. (2016). Standar Kompetensi Lulusan Pendidikan Dasar dan Menengah. In Lampiran Peraturan Menteri Pendidikan dan Kebudayaan Republik Indonesia Nomor 20 Tahun 2016.

Rachmawati, R. (2018). ANALISIS KETERKAITAN KOMPETENSI INTI ( KI ), DAN KOMPETENSI DASAR ( KD ). Diklat Keagamaan, XII, 231-239.

Rahmawati, D., \& Anggraini, A. D. (2017). Evaluasi Program Kurikulum Berdasarkan Standar Isi, Standar Proses, Dan Standar Kompetensi Lulusan Di Sdn Pisangan Timur 10 Pagi. Jurnal Pendidikan Ekonomi Dan $\begin{array}{lll}\text { Bisnis } & \text { (JPEB), } & \text { 5(1), }\end{array}$ 
152 Analisis Kebijakan Dan Pengelolaan Pendidikan Dasar Tentang Standar Kompetensi Lulusan Di Sekolah Dasar - Mera Putri Dewi, Sufyarma Marsidin, Ahmad Sabandi

DOI: 10.31004/edukatif.v2i2.117

https://doi.org/10.21009/jpeb.005.1.3

Suryati, A., Rochan, C., \& Nurmila, N. (2019).

Analisis Standar Kompetensi Kelulusan Di

Sdn 231 Sukaasih Bandung. Jurnal

Pendidikan Glasser, 3(1), 104.

https://doi.org/10.32529/glasser.v3i1.214

Zaini, H. (2015). Karakteristik Kurikulum 2013 Dan Kurikulum Tingkat Satuan Pendidikan (Ktsp). El-Idare: Journal of Islamic Education Management, 1(01), 15-31.

Zed, M. (2014). Metode Penelitian Kepustakaan. Jakarta: Yayasan Pustaka Obor Indonesia. 